\title{
Implicações do neoliberalismo para a educação infantil: um relato de experiência
}

\author{
Neoliberalism's implications for early childhood education: an account \\ of experience
}

\author{
Luciano Barbosa de Queiróz* \\ Universidade Federal de Goiás
}

Jeorge Luis Aguiar Barbosa**

Universidade Federal de Goiás
Lucas Cândido Campos***

Universidade Federal de Goiás

Ida Celine Gonçalves Santos****

Universidade Federal de Goiás

Amanda Pereira Borges de Souza*****

Universidade Federal de Goiás

Resumo Este artigo é um relato de experiência acerca de um Curso de Formação exclusivamente destinado às auxiliares de atividades educativas da Rede Municipal de Educação (RME) de Goiânia e desenvolvido por estagiários de Licenciatura em Psicologia, sob supervisão. Dentro de uma concepção crítica e transformadora de estágio, foram aplicadas duas fichas, uma de identificação e outra de avaliação, em alunas do curso. Os dados sugeriram, após análise, que estratégias de contenção de gastos e "enxugamento" da máquina pública através da contratação temporária se somam ao atual contexto de grave crise econômica e fiscal, resultando em piores condições de trabalho, a perda de sua qualidade e o desvirtuamento das orientações para a Educação Infantil no município.

PALAVRAS-CHAVE: Estágio; Educação infantil; Neliberalismo.

Abstract This article is an account of experience about a Training Course exclusively for the auxiliary educational activities of Municipal Education Network (RME) of Goiânia and developed by trainees of undergraduate course (teaching degree) in Psychology, under supervision. Within a critical and transformative conception of the internship, two cards were applied, one of identification and another of evaluation, in course students. The data suggested, after analysis, that strategies to contain expenses and "downsizing" of the public machine through temporary contracting are added to the current context of serious economic and fiscal crisis, resulting in worse working conditions, loss of quality and distortion of the guidelines for Early Childhood Education in the municipality.

KEYWORDS: Internship; Early childhood education, Neoliberalism. 


\section{Introdução}

Este artigo é um relato de experiência acerca de um Curso de Formação exclusivamente destinado às auxiliares de atividades educativas da Rede Municipal de Educação (RME) de Goiânia e desenvolvido por estagiários de Licenciatura em Psicologia, sob supervisão, em uma parceria da Universidade Federal de Goiás (UFG) com a Secretaria Municipal de Educação (SME). Para tanto, partiu-se de uma concepção crítica, transformadora e engajada de estágio que articula ensino, pesquisa e extensão, e que supera a visão praticista, instrumental, que tradicionalmente o definiu. O estágio é conceituado como um campo de conhecimento, como interface da tensão imanente à relação teoria e prática, como espaço de diálogo entre os desafios que a prática coloca à teoria, modificando-a, e entre as contribuições da teoria para uma prática refletiva e socialmente orientada (PIMENTA \& LIMA, 2005/2006; MIRANDA, 2008).

Partiu-se também de uma perspectiva crítica sobre a relação entre Psicologia e Educação, pela qual se defende a importância da Psicologia para se compreender a prática pedagógica e os fenômenos escolares, porém, ela, sozinha, não é suficiente para explicá-los e superar seus desafios (MIRANDA, 2008). Assim, o Curso de Formação não objetivou a redução das demandas e problemas colocados pelas auxiliares educativas às soluções que supostamente as teorias psicológicas apresentam, mas garantir às alunas vez e voz, um espaço democrático de formação entre iguais e voltado a uma formação para a emancipação, para a liberdade e para a transformação refletida da realidade.

Dentro de uma concepção de estágio que seja denúncia e resistência ao projeto neoliberal de conversão da Educação em mercadoria e que seja capaz de contribuir para a constituição de uma sociedade mais justa, foram aplicadas duas fichas, uma de identificação e outra de avaliação, em alunas do Curso de Formação. Os dados sugeriram, após análise, que estratégias de contenção de gastos e "enxugamento" da máquina pública através da contratação temporária se somam ao atual contexto de grave crise econômica e fiscal, resultando em piores condições de trabalho, a perda de sua qualidade e o desvirtuamento das orientações para a Educação Infantil no município, que se torna cada vez mais voltada para o mero cuidar, isto é, da assistência em alimentação, higiene e proteção, em detrimento de sua articulação com o Brincar e o Educar. Verificaram-se também diferenças entre as profissionais efetivas e contratadas em relação à formação continuada, certamente com implicações diretas para sua atuação.

\section{Contextualização da experiência}

\section{A proposta político-pedagógica para a rede municipal de Goiânia}

Em sintonia com os princípios legais vigentes nacionalmente, foi elaborada pela Rede Municipal de Educação (RME) de Goiânia a Proposta Político-Pedagógica (PPP) para a Educação Infantil da cidade, intitulada: "Infâncias e Crianças em cena: por uma Política de Educação Infantil para a Rede Municipal de Educação de Goiânia" (GOIÂNIA, 2014). Este documento visa a apresentar princípios com uma 
determinada concepção de Educação Infantil, de crianças, infâncias, e seu processo de desenvolvimento e aprendizagem. A perspectiva apresentada pela PPP serve como parâmetro, como fundamento à RME, para que todas as instituições de Educação Infantil do município se apoiem para elaborarem suas próprias Propostas Político-Pedagógicas e, a partir delas, suas práticas educativas.

A PPP para a RME de Goiânia adotou como base teórica a Pedagogia da Infância, um campo de estudos e pesquisas fundamentado na abordagem histórico-cultural e que tem como objeto de análise a criança e seus processos relacionais. Essa perspectiva compreende a criança enquanto sujeito social e concreto, valorizando assim sua cultura e seu espaço social. Essa teoria preocupa-se por conhecer a criança, dando ênfase aos processos de sua interação com seus pares e às mediações realizadas pelos profissionais de Educação (GOIÂNIA, 2014).

Assim, a Pedagogia da Infância preocupa-se com as relações educativas, em um espaço de convivência coletivo, ou seja, compreende que a criança aprende com o "outro" em contextos e relações sociais culturalmente mediados. A concepção de Educação Infantil presente na Proposta Político-Pedagógica para o município de Goiânia tem três pilares fundamentais: o Brincar, o Cuidar e o Educar (GOIÂNIA, 2014). Esses pilares se articulam intrinsecamente para a garantia do desenvolvimento e da aprendizagem plenos, integrais, das crianças.Porém, mesmo com todas as conquistas em direitos na Educação Infantil, a partir da década de 1990 e inserindo-se em uma agenda neoliberal para a educação latino-americana encabeçada por agências internacionais, como o Fundo Monetário Internacional (FMI) e o Banco Mundial (BM), o Estado brasileiro passou por uma reforma sistemática, com a entrada franca dos organismos internacionais na vida social, política e econômica brasileira e com a consolidação das medidas neoliberais no campo dos direitos sociais. Dessa forma, passa-se, cada vez mais, de um Estado legalmente responsável por oferecer uma educação pública, gratuita e de qualidade para um Estado gestor e regulamentador dos "serviços" oferecidos pelo setor privado da Educação (HYPOLITO, 2010; MORAES, 2002).

\section{Neoliberalismo: uma agenda perversa para a sociedade}

O neoliberalismo pode ser conceituado como uma narrativa que, enquanto tal,difunde ideias, imagens e valores que concorrem para uma determinada explicação do mundo e das dissonâncias e contradições de uma sociedade dividida em classes (MORAES, 2002). A partir da década de 1970, o neoliberalismo constituiu-se como pensamento defendido pelas principais potências econômicas, especialmente Inglaterra e Estados Unidos, que tentavam consolidá-lo como hegemônico. Ele emerge a partir da falência do modelo de regime monetário acordado no pós-guerra, inspirado no keynesiano; o esgotamento dos modos de acumulação capitalistas e suas instituições correspondentes; e a crise do intervencionismo estatal para promover desenvolvimento econômico, bem-estar e pleno emprego (ARCE, 2001; MORAES, 2002).

Ao propor a supremacia do mercado na regulação da vida social e institucional, o neoliberalismo ataca especialmente o modelo de Estado intervencionista a partir de três principais argumentos: esse modelo de Estado é oneroso e seus custos 
são crescentes, gerando crise fiscal e inflação; o intervencionismo "vicia" o comportamento de indivíduos, grupos sociais e empresas, impedindo a livre concorrência e a livre iniciativa; e ele também "contamina" os processos decisórios e o funcionamento das instituições democráticas, com aumento da corrupção e da burocracia (MORAES, 2002). Assim, o Estado deve ser mínimo para que o mercado "discipline" trabalhadores, empresas e instituições para que, em um contexto de livre concorrência, permita baixos custos, baixa inflação, e mínimo endividamento.

Além disso, Melo (2005) elenca as principais características da nova fase de acumulação capitalista chamada de neoliberal ou financeira: o conhecimento como principal força produtiva e aspecto central na nova divisão internacional do trabalho (países subdesenvolvidos são dependentes de tecnologia enquanto os desenvolvidos são os produtores); priorização da esfera privada em detrimento da esfera pública; aumento do desemprego, novas exigências de qualificação da mão de obra e sucateamento e extinção de políticas públicas em áreas sociais; e fortalecimento de políticas impositivas e "de ajuste" sob pressão de agências financiadoras internacionais, como o Fundo Monetário Internacional (FMI) e o Banco Mundial (BM).

Foi com a crise do endividamento externo da maioria dos países latino-americanos, principalmente a partir da década de 1970 e ainda mais gravemente na década seguinte, que a agenda neoliberal foi imposta a esses países pelas agências de financiamento internacionais (MELO, 2005; MORAES, 2002). Tal crise, juntamente com uma inflação galopante, aumento do desemprego, da extrema pobreza e das manifestações populares, foi um dos mais importantes fatores para a extinção das ditaduras militares e a transição para a democracia. No Brasil, por exemplo, o neoliberalismo foi implantado a partir de 1990, no governo de Fernando Collor de Mello (1990-1992), na tentativa de inserir o mercado brasileiro na esteira da globalização, conter gastos e aumentar o nível de investimento estrangeiro no país, bem como as linhas de crédito junto às agências de empréstimo internacionais.

Dentro das medidas de "reforma do Estado" na América Latina e na tentativa de "modernizar" esses países em contexto de globalização sem alterar a dependência a que eles se submetem, a Educação tornou-se um dos principais alvos da agenda neoliberal. A partir de diretrizes e pactos firmados internacionalmente entre os representantes de cada país, o FMI, o BM, e a Organização das Nações Unidas para a Educação, Ciência e Cultura (UNESCO), algumas medidas foram implantadas nacionalmente a partir da década de 1990, mudando as políticas educacionais até então adotadas e o papel do Estado até então firmado. Assim, acordou-se que as operações do Estado deveriam ser descentralizadas ou privatizadas, como educação, saúde e previdência, enquanto a ele caberia prioritariamente a regulamentação e fiscalização dos "serviços" da iniciativa privada (HYPOLITO, 2010; MELO, 2005).

Conforme Hypolito (2010), algumas das medidas neoliberais na Educação adotadas pelo Brasil desde a década de 1990 são: redefinição dos currículos de cursos de Licenciatura e de Pedagogia, priorizando um saber-fazer em detrimento de uma formação crítico-reflexiva; redefinição das agências de formação de professores, que deixam de ser prioritariamente as universidades e passam a ser os institutos federais e 
as escolas normais; incentivo a modalidades heterodoxas de formação de professores, como educação a distância, programas especiais e cursos semipresenciais; implantação de parâmetros de avaliação externa da prática docente a partir da aplicação de exames padronizados e em larga escala; e implantação de modelos de gestão que ampliem o controle da prática docente, do currículo e da própria gestão escolar.

Consequentemente, a Educação Infantil, como uma das etapas da educação básica, conforme a LDB de 1996 (BRASIL, 1996), não escapa à inversão que a agenda neoliberal impôs ao país em relação à Educação. Verifica-se, em Goiânia, por exemplo, a ampla contratação temporária de auxiliares de atividades educativas em detrimento da realização de concursos públicos para a sua efetivação, com implicações nas condições de trabalho e valorização profissional. Além disso, houve a municipalização de instituições anteriormente estaduais sem a necessária adaptação das instalações físicas, bem como o valor por aluno transferido aos centros municipais não acompanha a inflação.

Também não se verificou a expansão dos centros de Educação Infantil de forma a acompanhar a demanda, havendo, pois, um déficit na quantidade de vagas ofertadas ante a necessidade da população. Apesar da municipalização e criação de novos CMEIS, a acentuada urbanização de Goiânia e, consequentemente, o aumento de demanda por serviços públicos tornaram o acesso aos CMEIS uma grave questão social e política no município. Nas eleições municipais de 2016, por exemplo, a construção de mais CMEIS e a expansão de vagas foi pauta de todos os candidatos à prefeitura. Finalmente, a precarização das condições de trabalho das auxiliares de atividades educativas em nome da contenção de gastos e das diretrizes neoliberais para a educação básica inviabilizam a própria concretização das orientações da Proposta Político-Pedagógica municipal, da LDB e, em última instância, do ECA (BRASIL, 1996) e da Constituição (BRASIL, 1988).

\section{Experiência do curso}

\section{Percurso}

Todas as atividades e experiências foram desenvolvidas nas disciplinas de “Estágio Supervisionado em Formação de Professores de Psicologia”I e II (ESFPP-I e II), sendo que o objetivo geral de ambas as disciplinas consiste em "refletir sobre a formação de professores de Psicologia para a educação, tendo como ênfase a elaboração, execução e avaliação de um curso de formação destinado às auxiliares educativas dos Centros Municipais de Educação Infantil de Goiânia”. Tais disciplinas compõem o estágio de Licenciatura em Psicologia e são matérias obrigatórias para os licenciandos.

No segundo semestre letivo de cada ano, é oferecido um Curso de Formação às auxiliares de atividades educativas pelos licenciandos, sob supervisão. Trata-se de uma parceria entre a Universidade Federal de Goiás (UFG) e a Secretaria $\mathrm{Mu}$ nicipal de Educação (SME) firmada desde 2010, e se destina exclusivamente a essa categoria profissional. A carga-horária do curso varia de 40 (quarenta) a 60 (sessenta) horas, sendo exigido um mínimo de $75 \%$ de presença das alunas. Ao final, é emitido um certificado para cada auxiliar matriculada no curso. 
No primeiro semestre de 2016, os licenciandos fizeram um estudo teórico sobre a Educação Infantil e os documentos que a regem no país e na cidade de Goiânia. Posteriormente, fizeram observações participantes em um CMEI e, finalmente, realizaram uma pequena intervenção dialógica com as profissionais da instituição, visando a que refletissem sobre suas práticas e seu papel no desenvolvimento das crianças. A partir dessa primeira etapa, os licenciandos planejaram e estruturaram um plano do Curso de Formação, cujo título foi "O papel da(o) auxiliar educativa(o) na Proposta da Educação Infantil da Rede Municipal de Goiânia",e tendo como referências a PPP para a RME de Goiânia (GOIÂNIA, 2014) e a abordagem histórico-cultural. Tal elaboração compôs a segunda etapa do estágio.

Finalmente, a terceira etapa do estágio consistiu na realização do curso no segundo semestre de 2016, com uma carga-horária de 40 (quarenta) horas, distribuídas em treze encontros semanais ${ }^{1}$. O curso foi fundamentado na abordagem históricocultural de Lev Semenovich Vigotski (1896-1934) e teve como temas a história do atendimento à criança pequena; Pedagogia da Infância; o contexto histórico em que emergiu o pensamento de Vigotski; os conceitos de aprendizagem, desenvolvimento e mediação para essa abordagem; o papel da brincadeira e da afetividade no contexto da Educação Infantil; a diversidade; a sexualidade e a relação família/CMEI. O público-alvo caracterizou-se por auxiliares educativas da RME de Goiânia que atuam diretamente na Educação Infantil, sendo elas efetivas ou vinculadas por contrato especial.

\section{Concepção de estágio}

Para a elaboração do Curso de Formação, partiu-se de uma concepção de estágio que integra ensino, pesquisa e extensão e que supera a visão eminentemente praticista, instrumental, que tradicionalmente foi dado a ele. O estágio é visto como campo de conhecimento (PIMENTA \& LIMA, 2005/2016), como interface da tensão entre teoria e prática, como espaço de diálogo entre os desafios colocados pela prática às teorias e as contribuições das teorias a uma prática engajada e transformadora (PIMENTA \& LIMA, 2005/2006; MIRANDA, 2008). Assim, tentou-se evitar sempre a harmonização ou equação entre teoria e prática ou sua completa dicotomia, preservando as distâncias - e, portanto, a fecundidade - de uma relação eminentemente complexa, tensa e contraditória (MIRANDA, 2008).

Além disso, adotou-se uma perspectiva crítica da relação Psicologia e Educação. Se por um lado, reconhece-se a importância da Psicologia como um saber que contribui para se pensar a prática pedagógica e os fenômenos escolares, por outro lado, é necessária a superação da ideia que concebe a Psicologia como suficiente para explicá-los (MIRANDA, 2008). Não houve, pois, a pretensão, com o Curso de Formação, de reduzir todas as demandas das auxiliares às respostas que supostamente as teorias psicológicas poderiam dar, mas sim dar vez e voz às alunas, como sujeitos em sala de aula que contribuem para a sua formação e enriquecem a própria teoria a partir de suas práticas. 


\section{Procedimentos}

Durante a etapa de realização do curso, partindo de perspectivas críticas de estágio e de práticas escolares, os licenciandos fizeram encontros semanais de supervisão a fim de elaborarem planos de curso e de aulas condizentes com suas premissas e com os objetivos de uma formação integral, engajada e emancipadora para as auxiliares. Nessas supervisões, todos os licenciandos se reuniam com a supervisora e decidiam quais seriam os objetivos, metodologias e referências de cada aula.

A existência de um projeto em comum entre os licenciandos fez com que o trabalho se tornasse voltado para uma formação integral às auxiliares, partindo de uma concepção de Educação para a emancipação, para o exercício da humanidade dentro de um contexto de respeito entre iguais. Evidenciou-se a necessidade, com o acirramento dos conflitos e contradições entre movimentos populares (trabalho) e políticas neoliberais (capital), de se constituir a sala de aula como espaço de resistência ao discurso de ódio e à expropriação do direito a uma Educação como Direito Humano fundamental (MONTEIRO, 2003).

Durante o planejamento do curso e a elaboração do cronograma, ficou evidente a necessidade de se escolher métodos diversos, que deveriam variar de acordo com o tema da aula. Desse modo, utilizaram-se aulas expositivas e dialogadas; recursos audiovisuais, como vídeos e músicas; dinâmicas em grupo; e debates, considerando o contexto das alunas e a carga teórica do curso. Os licenciandos elaboraram, ainda, as atividades que seriam executadas em sala e atividades extraclasse, como exercícios de observação em ambiente externo e exposição de situações-problema a serem refletidos a partir do conteúdo aprendido na aula anterior.

Das 55 (cinquenta e cinco) auxiliares inscritas originalmente na turma, 40 (quarenta) iniciaram de fato, o curso, e 34 (trinta e quatro) concluíram o mesmo. Estas taxas de desistência e de evasão devem-se, provavelmente, às dificuldades oriundas do cotidiano cansativo ao qual se submetem as auxiliares educativas. Uma dessas dificuldades é a jornada dupla ou tripla enfrentada pela maioria delas, como explicitado pelas profissionais em diferentes momentos do curso. Além do cansaço, as auxiliares não são liberadas de suas funções profissionais para realizarem cursos de formação, dificultando o acesso e a permanência de muitas, visto que o deslocamento do local de trabalho até o local de realização do curso, em muitos casos, era demorado e carente de uma infraestrutura adequada.

\section{Resultados}

Foram aplicadas na turma duas fichas de avaliação: uma no início do curso, preenchida por 40 (quarenta) profissionais, para se conhecer melhor o perfil das auxiliares interessadas no curso de formação, e outra no final do curso, preenchida por 29 (vinte e nove) profissionais, com o intuito de avaliar as contribuições do projeto de formação realizado e os principais desafios da atuação profissional . Após a aplicação das fichas, os dados foram tabulados e tratados com o objetivo de se analisar a possível correlação entre a adoção das políticas neoliberais nas últimas décadas e as suas implicações para as condições de trabalho das profissionais. 
Gráfico 1 - Tipo de vínculo profissional com a Secretaria $\mathrm{Mu}-$ nicipal de Educação (SME) em porcentagem.

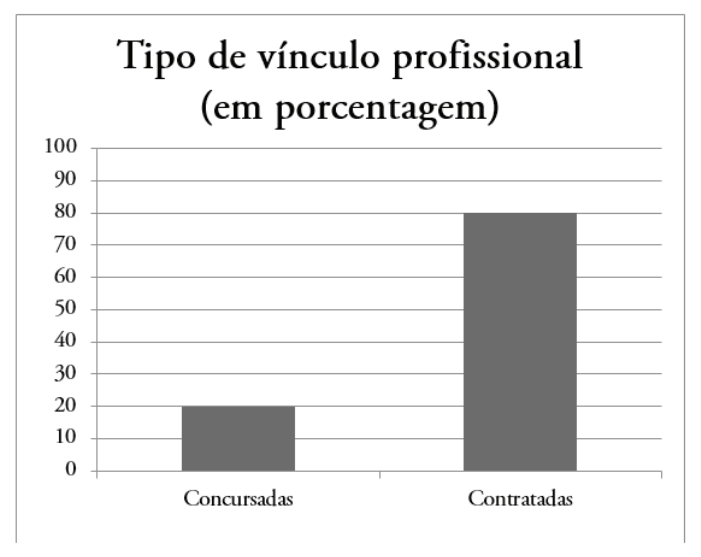

Os dados mostrados no Gráfico 1 sugerem que a maioria das auxiliares de atividades educativas da amostra pesquisada são contratadas (80\%) e que apenas 20\% são efetivas. As profissionais contratadas possuem o vínculo de dois anos com a Rede Municipal de Educação (RME), em regime de CLT (Consolidação das Leis do Trabalho) e não têm os mesmos benefícios das auxiliares efetivas, como Plano de Carreira.

Assim, a contratação "especial" dessas profissionais é uma forma de "amenizar" o orçamento municipal e implica em sérias consequências para as condições de trabalho, para a sua qualidade e para a saúde do trabalhador. Por exemplo, a categoria das auxiliares educativas é a única vinculada à RME que não é liberada para formação, fator este que fez com que o Curso de Formação acontecesse após o expediente, isto é, no período noturno. Além disso, grande parte tem dupla jornada, os salários são baixos e a contratação não exige formação superior para o trabalho nos CMEIs.

Gráfico 2 - Formação acadêmica da amostra de auxiliares pesquisada em porcentagem.

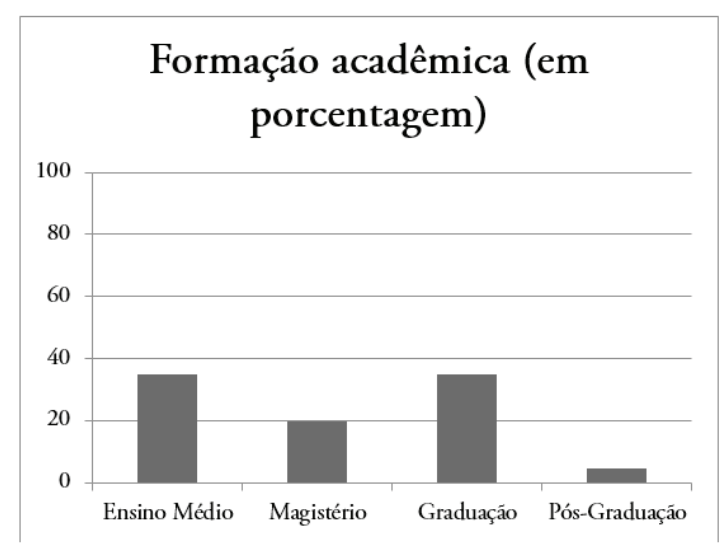


Conforme o Gráfico 2,35\% das auxiliares pesquisadas têm curso superior e 10\% tem pós-graduação. Mesmo a contratação não exigindo formação nesses níveis, verifica-se a sub-remuneração de profissionais de qualificação superior, que recebem o mesmo salário das que têm apenas o ensino médio (35\%). As políticas neoliberais de incentivo à criação e à expansão de faculdades e universidades privadas, com o aumento de matrículas, têm causado o crescimento no número de profissionais com formação superior mesmo em um mercado de trabalho cada vez mais "enxuto" e incapaz de absorver toda a mão de obra.

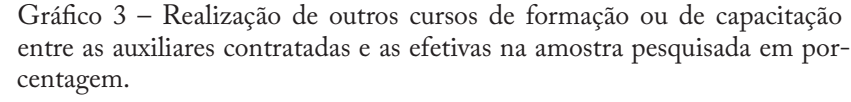

Gráfico 3 - Realização de outros cursos de formação ou de capacitação entre as auxiliares contratadas e as efetivas na amostra pesquisada em porcentagem.

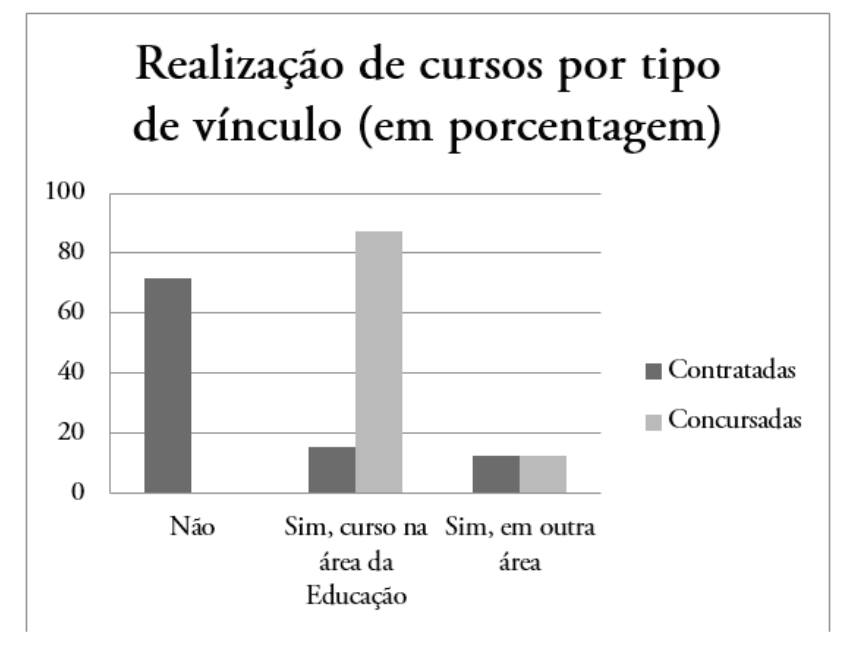

Os dados mostrados no Gráfico 3 sugerem as implicações do tipo de vínculo profissional para a formação continuada das auxiliares e, consequentemente, para as condições do trabalho e de sua qualidade. Enquanto $87,5 \%$ das auxiliares efetivas já realizou curso de formação na área pedagógica, apenas 15,63\% das auxiliares contratadas fez o mesmo. Por outro lado, $71,88 \%$ das auxiliares contratadas não realizou qualquer curso de formação anteriormente, enquanto nenhuma auxiliar efetiva respondeu isso. Portanto, as diferentes condições de vínculo institucional - e, claro, de remuneração e direitos trabalhistas - podem ser uma variável na maior ou menor procura das auxiliares por cursos de formação continuada, sendo fator de incentivo.

Ao adotar políticas neoliberais de "contenção de gastos", "enxugamento da máquina pública" e precarização das condições de trabalho, o governo municipal contribui para que as próprias diretrizes da Proposta Político-Pedagógica (PPP) sejam inviabilizadas em nome das premissas da ortodoxia político-econômica. Assim, tratase de se sobrepor os interesses econômico-financeiros em detrimentos dos interesses democrático-populares por uma educação de qualidade social e orientada para a formação integral do sujeito e sua emancipação. 
Luciano Barbosa de Queiróz - Jeorge Luis Aguiar Barbosa - Lucas Cândido Campos - Ida

Celine Gonçalves Santos - Amanda Pereira Borges de Souza

Gráfico 4 - Porcentagem da opinião das auxiliares da amostra pesquisa acerca do impacto do contexto de crise econômica e fiscal e as políticas de contenção de gastos por que passa o país.

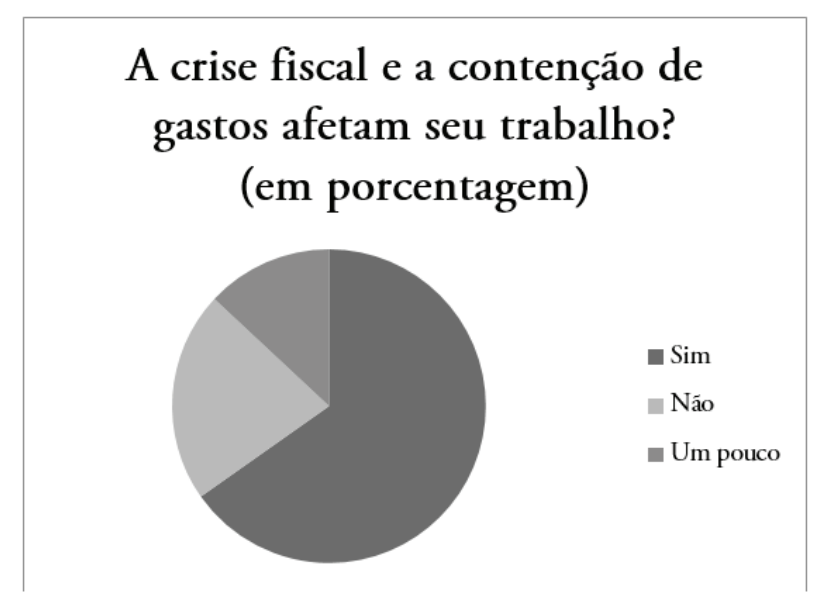

O Gráfico 4 mostra que $65,22 \%$ das auxiliares respondeu que o contexto de crise econômica e fiscal por que passa o país atualmente afeta o seu trabalho, sugerindo uma piora das condições de seu exercício e de sua qualidade. Esse contexto de grave crise se soma às já existentes estratégias de precarização e sucateamento, como a contratação "especial". Além disso, Gráfico 5 apresenta como a crise econômica e fiscal e as políticas de contenção de gastos afetam o trabalho das auxiliares. Observa-se que $76,47 \%$ respondeu que há falta de materiais de uso e consumo nos CMEIs, prejudicando as atividades cotidianas que deveriam ser feitas.

Gráfico 5 - Porcentagem da opinião das auxiliares da amostra pesquisada sobre como a crise econômica e fiscal e as políticas de contenção de gastos impactam em seu trabalho.

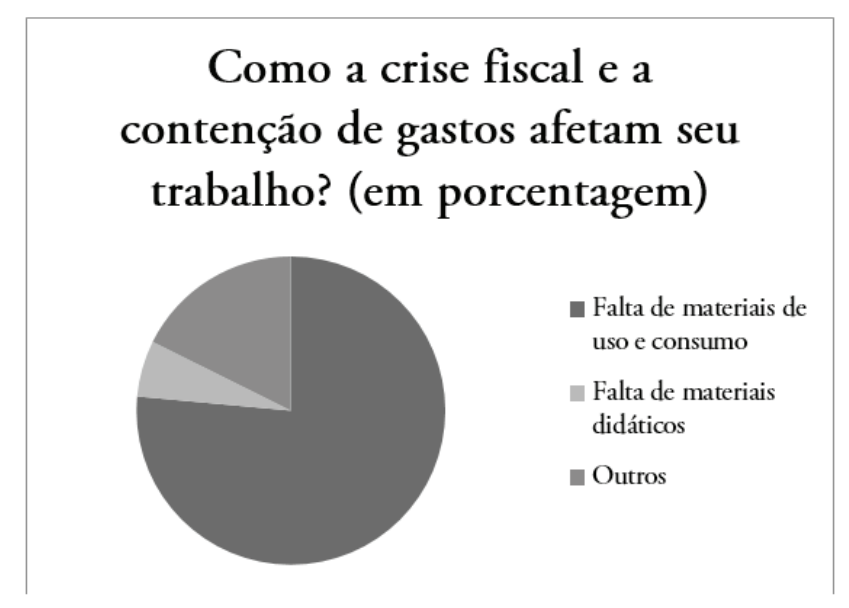


Algumas das respostas mais dramáticas à pergunta "O contexto de crise econômica e contenção de gastos em que o Brasil vive atualmente afeta seu trabalho? Como isso acontece?" e que revelam a piora das condições de trabalho nos CMEIs e a inviabilização das atividades que deveriam ser realizadas neles foram:

"Sim, falta dinheiro para os materiais e melhorias nas salas. Materiais de aula e até comida para as crianças";

"Sim, cortou-se muitas verbas que iam para o CMEI e às vezes falta o essencial para uma boa alimentação e produtos de limpeza";

"Afeta e muito porque nos CMEI já recebe uma renda muito pequena para cada criança e, com a crise que está no nosso país, neste ano foi muito difícil, mas estamos conseguindo passar, chegamos até a pedir ajuda para os pais e alunos com ajuda de materiais e outros".

Essas respostas indicam que a crise econômica e fiscal e a contenção de gastos pioraram ainda mais as condições de trabalho e de funcionamento nos CMEIs, inviabilizando atividades essenciais para a formação das crianças e até mesmo sua alimentação e cuidados básicos. Pode-se refletir também se tal contexto promove uma "regressão" na concretização das diretrizes elencadas na PPP para o município, fazendo com que o CMEI se centre, cada vez mais, no cuidado básico, no Cuidar, em detrimento do Brincar e do Educar, devido à falta de orçamento necessário e das condições mínimas para um trabalho voltado à formação integral da criança.

Gráfico 6 - Porcentagem da opinião das auxiliares da amostra pesquisada sobre a avaliação geral do curso.

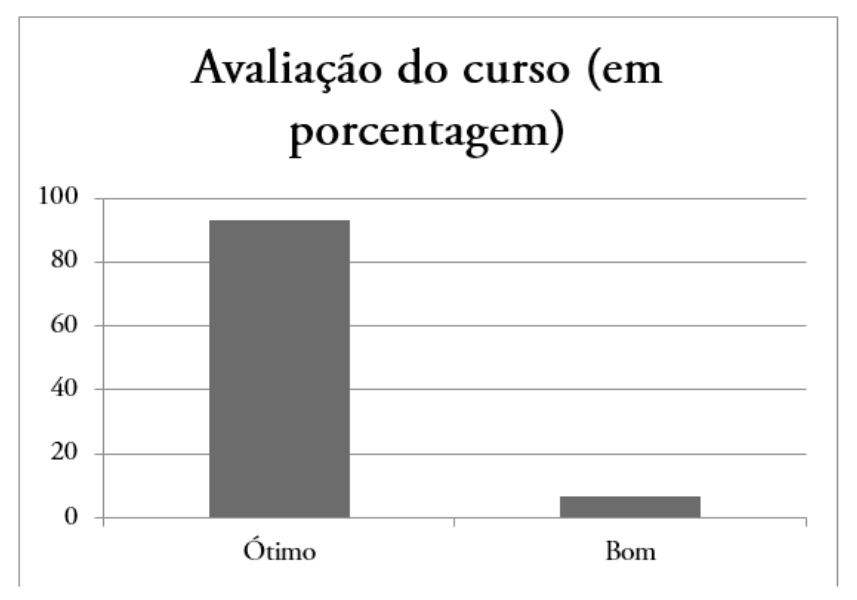


Gráfico 7 - Porcentagem da opinião das auxiliares da amostra pesquisada sobre a contribuição do Curso de Formação para a sua prática profissional.

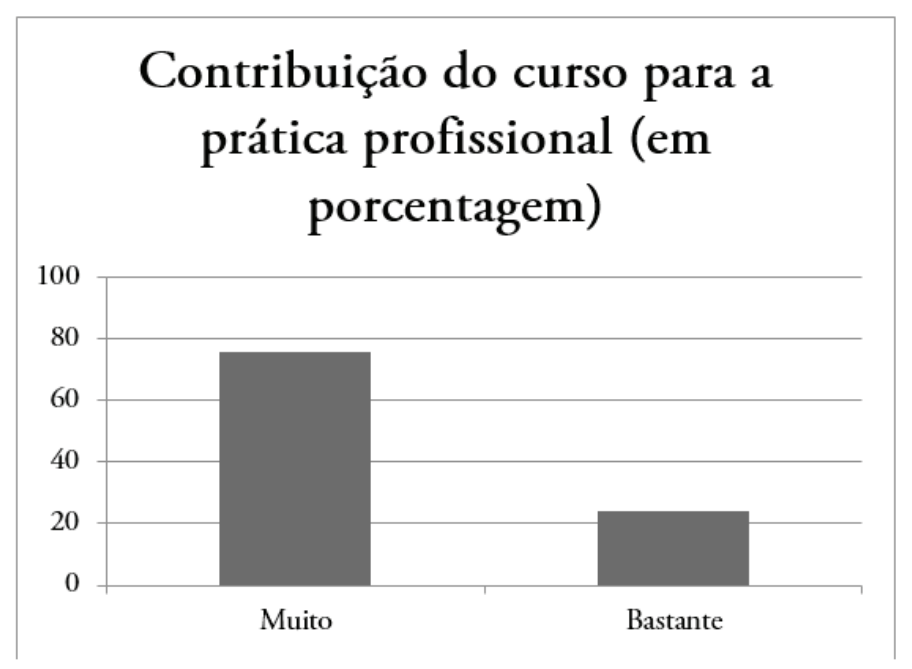

Os Gráficos 6 e 7 revelam que 93,1\% das auxiliares da amostra pesquisada avaliou o Curso de Formação como "Ótimo" e 75,86\% respondeu que ele contribuiu "Muito" para a sua prática profissional. Além disso, 6,897\% o avaliou como "Bom" e 24,14\% respondeu que ele contribuiu "Bastante" para a sua prática profissional. Ninguém da amostra pesquisada fez avaliação negativa do curso, mostrando para os licenciandos que o trabalho empreendido alcançou o objetivo de dar uma formação de qualidade, gratuita, pública e integral a todas as alunas.

\section{Considerações finais}

Ao entrarem em contato com a prática educativa, os licenciandos se depararam com as exigências da atuação do professor em estruturar e manejar as aulas; a manutenção de um espaço de diálogo democraticamente orientado com as auxiliares após um dia de trabalho exaustivo; a necessidade de uma educação pública, gratuita, de qualidade social e igualitária; a luta para que as políticas públicas em Educação Infantil sejam implementadas em sua integridade e para que a agenda neoliberal seja combatida, devido aos seus objetivos perversos em relação aos direitos sociais duramente conquistados.

A agenda neoliberal para a educação coloca em xeque a oferta de um serviço público de qualidade na Educação Infantil. Propostas como a terceirização e contratação temporária dos profissionais, com a consequente extinção da carreira pública, são medidas que desvalorizam a categoria dos educadores, desde o nível básico ao nível superior. Tais medidas trazem como provável consequência a implantação de uma lógica de mercado no serviço público. A lógica de funcionamento neoliberal permite o controle e a regulação dos salários através da demanda de profissionais e a oferta de vagas no mercado. 
A existência de um grande número de profissionais para ocupar as poucas vagas ofertadas (devido ao "enxugamento" da máquina pública), sob regime de CLT, acaba por dificultar a luta por melhorias das condições de trabalho e salariais por parte dos educadores, visto que estratégias como greves ou paralisações abrem margem para demissões. A predominância de profissionais contratados na RME de Goiânia (80\% da amostra pesquisada), a atual crise econômica e fiscal, e as políticas de contenção de gastos representam impasses e desafios à concretização das orientações presentes na PPP para o município de Goiânia, pautados na Pedagogia da Infância. Um grave desvirtuamento da PPP em contexto de grave crise orçamentária é o retrocesso do mero Cuidar, em detrimento de sua articulação efetiva com o Brincar e o Educar no espaço do CMEI.

\section{Referências}

ARCE, A. Compre o kit neoliberal para a educação infantil e ganhe grátis os dez passos para se tornar um professor reflexivo. Educação \& Sociedade: Revista do Centro de Estudos Educação e Sociedade, Campinas, v. 22, n. 74, p. 251-283, abr. 2001. Disponível em: <http://www.scielo. br/scielo.php?script=sci_arttext\&pid=S0101=73302001000100014-\&lng=pt\&nrm=iso\&tlngpt $>$. Acesso em: 30 jun. 2016.

BRASIL. Constituição da República Federativa do Brasil de 1988. Disponível em: <https:// www.planalto.gov.br/ccivil_03/constituicao/constituicao.htm>. Acesso em: 30 jun. 2016.

. Lei de Diretrizes e Bases da Educação Nacional (Lei n. 9394, de 20 de dezembro de 1996). Disponível em: <http://www.planalto.gov.br/ccivil_03/LEIS/L9394.htm>. Acesso em: 30 jun. 2016.

Estatuto da Criança e do Adolescente (Lei no 8.069, de 13 de julho de 1990). Disponível em: <http://www.planalto.gov.br/ccivil_03/leis/L8069.htm〉. Acesso em: 30 jun. 2016.

GOIÂNIA. Infâncias e Crianças em Cena: por uma Política de Educação Infantil para a Rede Municipal de Educação de Goiânia. Secretaria Municipal de Educação. Goiânia: SME, DEPE, DEI, 2014. Disponível em: <http://educacaoinfantilrmegoiania.blogspot.com.br/p/publicacoes -legais.html>. Acesso em: 30 jun. 2016.

HYPOLITO, A. M. Políticas Curriculares, Estado e Regulação. Educação \& Sociedade: Revista do Centro de Estudos Educação e Sociedade, Campinas, v. 31, n. 113, p. 13371354, out-dez.2010. Disponível em: <http://www.scielo.br/scielo.php?script=sci_arttext\&pi$\mathrm{d}=$ S0101-73302010000400015\&lng=pt\&nrm=iso\&tlng=pt $>$. Acesso em: 30 jun. 2016.

MELO, A. A. S. A mundialização da educação: neoliberalismo e social-democracia no Brasil e na Venezuela. Trabalho, Educação e Saúde: Revista da Escola Politécnica de Saúde Joaquim Venâncio da Fundação Oswaldo Cruz, Rio de Janeiro, v. 3, n. 2, p. 397-408, 2005. Disponível em: <http://www.scielo.br/scielo.php?script=sci_arttext\&pi$\mathrm{d}=\mathrm{S} 1981-77462005000200008 \& \operatorname{lng}=\mathrm{pt \& nrm}=\mathrm{iso} \& \mathrm{tlng}=\mathrm{pt}>$. Acesso em: 30 jun. 2016.

MIRANDA, M. G. A Psicologia da Educação na perspectiva da relação teoria e prática: uma conciliação possível? In: MIRANDA, M. G.; RESENDE, A. C. A. Escritos de Psicologia, educação e cultura. Goiânia, UCG, 2008.

MONTEIRO, A. R. O pão do direito à educação. Educação \& Sociedade: Revista do Centro de Estudos Educação e Sociedade, Campinas, v. 24, n. 84, p. 763-789, set. 2003. Disponível em: <http://www.scielo.br/scielo.php?script=sci_arttext\&pi-

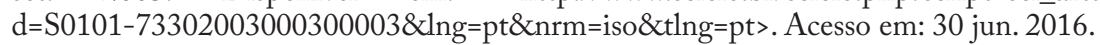


Luciano Barbosa de Queiróz - Jeorge Luis Aguiar Barbosa - Lucas Cândido Campos - Ida

Celine Gonçalves Santos - Amanda Pereira Borges de Souza

MORAES, R. C. Reformas neoliberais e políticas públicas: hegemonia ideológica e redefinição das relações estado-sociedade. Educação \& Sociedade: Revista do Centro de Estudos Educação e Sociedade, Campinas, v. 23, n. 80, p. 13-24, set. 2002. Disponível em: <http://www.scielo. br/scielo.php?script=sci_arttext\&pid=S0101=73302002008000002-\&lng=pt\&nrm=iso\&tlngpt>. Acesso em: 30 jun. 2016.

PIMENTA, S. G.; LIMA, M. S. L. Estágio e docência: diferentes concepções. Revista Poiésis, v. 3, n. 3 e 4, p. 5-24, 2005/2006. Disponível em: <https:/www.revistas.ufg.br/poiesis/article/ view/10542>. Acesso em: 30 jun. 2016.

Notas

\begin{abstract}
${ }^{1}$ Inscreveram-se para o curso 113 (cento e treze) auxiliares, que foram divididas em duas turmas de aproximadamente 55 (cinquenta e cinco) alunas. Cada turma possuía de cinco a seis professores, que ministravam suas aulas em duplas rotativas.

* Graduando em Psicologia pela Universidade Federal de Goiás, Goiânia, Goiás, Brasil.

** Graduando em Psicologia pela Universidade Federal de Goiás, Goiânia, Goiás, Brasil.

*** Graduando em Psicologia pela Universidade Federal de Goiás, Goiânia, Goiás, Brasil.

***** Graduada em Psicologia e Ciências Sociais pela Universidade Federal de Goiás, Goiânia, Goiás, Brasil.

****** Graduanda em Psicologia pela Universidade Federal de Goiás, Goiânia, Goiás, Brasil.
\end{abstract}

\title{
Correspondência
}

Luciano Barbosa de Queiróz - Universidade Federal de Goiás. Rua 235, Setor Leste Universitário. CEP: 74605050. Goiânia, Goiás, Brasil.

E-mail: lucianobarbosadequeiroz.nerd@gmail.com - jeorgelbarbosa@gmail.com - lucascamposgyn@gmail. com - icgs.eaje@gmail.com - amanda_ipe@hotmail.com

Recebido em 17 de dezembro de 2016

Aprovado em 10 de março de 2017 